\title{
Relações interpessoais entre os profissionais da saúde do Consultório na Rua
}

\section{Interpersonal relationships among healthcare professionals in the Street Clinic}

\author{
Eliana Rustick Migowski \\ Santa Casa de Misericórdia de Porto Alegre - Porto Alegre - Brasil \\ elianamigowski@gmail.com \\ Sérgio Almeida Migowski \\ Instituto Federal de Educação, Ciência e Tecnologia do Rio Grande do Sul - IFRS - Porto Alegre - Brasil \\ sergiomigowski@gmail.com \\ Cláudia de Souza Libânio \\ Universidade Federal de Ciências da Saúde de Porto Alegre - UFCSPA - Porto Alegre - Brasil \\ clasl@terra.com.br
}

\section{Resumo}

Este estudo objetivou analisar o impacto das relações interpessoais entre os profissionais da saúde do Consultório na Rua de uma capital da Região Sul do Brasil no atendimento à população em situação de rua. O Consultório na Rua é responsável pelo acesso a serviços de saúde de toda a população em situação de rua daquele município. Com uma pesquisa qualitativa, foram entrevistados os profissionais que fazem parte desse serviço em adição à análise documental e à observação participante. Como a equipe foi composta por profissionais contratados por organizações distintas, foi possível evidenciar uma resistência inicial ao trabalho em equipe. Por outro lado, à medida que as relações interpessoais entre os membros da equipe eram construídas, foi percebido um aumento na sua satisfação e no comprometimento com o trabalho. Isso acabou por se refletir na construção de relações interpessoais também com a população em situação de rua, possibilitando a construção de vínculos e a promoção da confiança, o que permitiu o acolhimento a pessoas que normalmente têm uma percepção de invisibilidade pelo restante da sociedade.

Palavras-chave: relações interpessoais, pessoas em situação de rua, políticas de saúde.

\section{Abstract}

This study aimed to analyze the impact of interpersonal relationships among the healthcare professionals of the Street Clinic in a capital of Southern Brazil, when serving the homeless population. The Street Clinic is responsible for the entire homeless population of this municipality access to health services. A qualitative research was conducted with an interview with professionals who are part of this service, document analysis and participant observation. As the team included professionals hired by different organizations, an initial resistance to teamwork was seen. On the other hand, as interpersonal relationships between team members were built, an increase in their 
satisfaction and commitment to work was noticed. This was reflected in the construction of interpersonal relationships also with the homeless population. The consequent construction of bonds and promotion of trust allowed welcoming people who usually feel invisible to society.

Keywords: interpersonal relationships, homeless, health policies.

\section{Introdução}

O aumento da população em situação de rua é diretamente proporcional ao aumento da crise econômica em todo o Brasil, notadamente nas grandes cidades. Estudo recente do Instituto de Pesquisa Econômica Aplicada (IPEA) relatou a existência de 101 mil pessoas em situação de rua em todo o Brasil no ano de 2016. Em fevereiro de 2020, 146 mil pessoas declararam-se nessa situação no cadastro único do governo federal ante uma estimativa de pesquisadores do IPEA de haver, na realidade, 222 mil pessoas em situação de rua (SILVA; NATALINO; PINHEIRO, 2020). Usualmente, trata-se de um grupo bastante heterogêneo, composto por desempregados, egressos do sistema penitenciário, imigrantes, oriundos de problemas familiares, dentre outros. Comum a todos são a pobreza e a extrema vulnerabilidade, além da falta de acesso aos direitos mais básicos da cidadania (TEIXEIRA; ENGSTROM; TAVARES, 2019).

Como política pública, buscando proporcionar acesso à saúde a essa parcela da população, foram criados os Consultórios na Rua, previstos pela Política Nacional de Atenção Básica desde 2011 (SILVA; NATALINO; PINHEIRO, 2020). Em maio de 2020, existia, em uma capital da Região Sul do Brasil, uma única Unidade Básica de Saúde vinculada à prefeitura, para atender a cerca de 4.000 pessoas em situação de rua, número que, por conta da crise econômica e dos reflexos econômicos oriundos da pandemia da COVID-19, vem aumentando. Ela conta com a atuação de médicos, enfermeiros, dentista, psicólogo, assistente social, técnicos em enfermagem, assistente de saúde bucal e agente social (GLOBO, 2020; JORNAL DO COMÉRCIO, 2020).

Gerenciado pela prefeitura municipal de uma das capitais da Região Sul do Brasil, esse Consultório na Rua é composto por profissionais contratados por um hospital filantrópico localizado na mesma capital que, em regime de parceria, fornece os profissionais da saúde necessários à operacionalização do setor. Suas atividades não se restringem ao atendimento na Unidade Básica de Saúde, mas também incluem a busca ativa todos os dias da semana, quando uma parte da equipe, composta por enfermeiro, médico, psicólogo, dentista, agente social e técnico em enfermagem, vai às ruas para realizar a abordagem daqueles cidadãos (PREFEITURA DE PORTO ALEGRE, 2019a, 2019b).

Em uma equipe multiprofissional como essa e com um público-alvo com tantas peculiaridades, a capacidade de desenvolver relações interpessoais parece ser condição indispensável para o êxito das atividades, principalmente quando se leva em conta o trabalho fragmentado que pode ocorrer em serviços de saúde (DA SILVA et al., 2017). Os relacionamentos são interdependentes por natureza e o seu resultado impacta diretamente os envolvidos nele. Isso afeta o grau de comunicação e confiança que vai sendo construído e no suporte das lideranças envolvidas, o que influencia a própria motivação e o comprometimento individuais (FRYER; TUCKER; SINGER, 2018; LE et al., 2018).

Como a qualidade da interação entre as lideranças e os profissionais operacionais tem uma relação positiva com o engajamento desses profissionais e, por consequência, nos serviços prestados (YEE; GUO; YEUNG, 2015), este estudo objetiva analisar o impacto das relações interpessoais entre os profissionais da saúde desse Consultório na Rua no atendimento à população em situação de rua. 


\section{Referencial teórico}

Os serviços têm particularidades que tornam o relacionamento ainda mais relevante entre aqueles que os prestam e aqueles que os recebem. A intangibilidade, a simultaneidade, a perecibilidade e a variabilidade são fatores que dificultam a operação de serviços (XING et al., 2013), pois demandam a construção de um ambiente de trabalho que permita que as falhas sejam discutidas de maneira transparente, sob pena de causar desconforto tanto em quem produz os serviços quanto na qualidade de quem os recebe (TUCKER, 2007).

A intangibilidade significa que os serviços não envolvem materiais tangíveis, apesar de serem necessários em alguns momentos para a sua prestação, como é o caso de seringas, medicamentos, exames e curativos. A simultaneidade significa que a produção do serviço por alguém tem seu consumo concomitante por outro indivíduo. Além disso, como não se pode armazenar serviço, ele é perecível, além de ser bastante variável, uma vez que é prestado por diferentes pessoas para pessoas com necessidades e expectativas distintas (XING et al., 2013).

Quando se trata da prestação do serviço assistencial, a variabilidade/incerteza pode levar não só a dificuldades na integração dos membros de uma equipe, como à redução da sua eficiência (PARNABY; TOWILL, 2008). Uma vez que, em geral, possuem causas internas (BÖHME et al., 2014), demandam ações da gestão para mitigá-las, o que implica melhorias na comunicação e na construção da confiança entre seus membros (PARNABY; TOWILL, 2008).

Nos serviços de saúde, a liderança também significa desenvolver a habilidade de inspirar a excelência individual e organizacional, permitindo o desenvolvimento de uma visão compartilhada do que se deseja conseguir. Para tal, é necessário envolver os demais membros, utilizando-se de uma negociação clara, de forma que se sintam apoiados e motivados a colaborar, o que demanda um estilo de liderança capaz de construir um grau de autonomia e de confiança entre os membros da equipe (CLIFF, 2012).

Ao se sentirem parte do processo e de perceberem que o seu esforço contribui de forma decisiva na atividade assistencial (GALLETTA et al., 2016), os profissionais de enfermagem, em especial, acabam aumentando sua satisfação no trabalho e, por consequência, seu comprometimento, produtividade e espírito de cooperação (YOON; $\mathrm{KIM}$; SHIN, 2016). Contribui ainda mais para a qualidade dessas relações interpessoais a comunicação entre os profissionais médicos e de enfermagem (GALLETTA et al., 2016).

Satisfação pessoal e comprometimento ganham ainda mais vulto, quando o foco da atividade assistencial é o atendimento da população em situação de rua. Tendo como base o princípio doutrinário da universalidade que, juntamente com a integralidade e a equidade, conferem legitimidade ao Sistema Único de Saúde (SUS), o Consultório na Rua existe para acolher uma parcela da população em situação de exclusão social e que, não raro, se autoexclui, a fim de lhes proporcionar uma porta de entrada no sistema de saúde (BRASIL, 2010).

Com a circulação dessa equipe multiprofissional nas ruas em busca ativa da população em situação de rua, busca-se a construção de vínculos, de relacionamentos de confiança por meio da promoção do acolhimento e de uma escuta cultural qualificada (VASCONCELOS; PARREIRA, 2017), para conhecer as demandas e necessidades dessa população, o que acaba sendo a ponte para promover o acesso à saúde. Esse trabalho leva à necessidade de saber colocar-se no lugar do outro, desenvolvendo a empatia (DUARTE, 2018), o que só é possível se os profissionais da saúde se sentirem comprometidos com o trabalho que realizam (YOON; KIM; SHIN, 2016).

Duarte (2018) denomina esse comprometimento como persistência acolhedora, o que implica considerar a confiança perdida dessa parcela da população nas relações de 
vínculo, diante das discriminações sofridas diariamente e da sua percepção de invisibilidade perante o restante da sociedade. Diante desse contexto, é ainda mais relevante a construção das relações interpessoais entre os profissionais que compõem o Consultório na Rua, uma vez que indivíduos que vivem em ambientes onde uns cuidam dos outros tendem a cuidar e se preocupar com os outros, sejam eles conhecidos ou estranhos. Ambientes como esses têm, ainda, a qualidade de proteger seus membros contra o estresse e o ressentimento que podem surgir durante o auxílio dado a indivíduos com grandes necessidades de cuidado (LE et al., 2018).

\section{Método}

Como este estudo tem por finalidade compreender os fenômenos por meio de suas relações de causa e efeito, além de identificar quais são os elementos determinantes para a ocorrência de determinados fenômenos, ele é definido como explicativo e descritivo quanto aos objetivos (KLEIN; SILVA; MACHADO, 2015). Em relação ao método de procedimentos técnicos, o trabalho será um estudo de caso único, cujo objeto de análise é o Consultório na Rua existente em uma capital da Região Sul do Brasil.

O estudo baseou-se no paradigma qualitativo, caracterizado por ser um estudo aprofundado de um sistema em seu determinado ambiente e por normalmente envolver pessoas (KLEIN; SILVA; MACHADO, 2015). Foram feitas entrevistas semiestruturadas com uma enfermeira, doravante denominada $E 1$, quatro técnicos em enfermagem (T1...T4, de acordo com a ordem em que foram entrevistados), uma assistente de saúde bucal (S1), uma agente social (A1), um dentista (D1), uma psicóloga (P1) e os dois médicos (M1; M2) que desempenham suas atividades no Consultório na Rua. A outra enfermeira que compõe a equipe é autora deste estudo e participou somente por meio da observação participante e da análise documental no relatório de metas, durante o período de janeiro a maio de 2020.

A equipe atual é composta de antigos membros da organização responsável pela gestão dos recursos humanos em período anterior ao hospital filantrópico e pelos novos membros contratados por esta. Como o final do contrato com aquela organização fora objeto de sucessivas ações judiciais para a manutenção daqueles funcionários, o hospital filantrópico optou pela oferta de vagas aos oriundos daquela organização, com as vagas remanescentes sendo direcionadas para recrutamento externo.

Os autores elaboraram um roteiro de entrevista semiestruturada com o objetivo de verificar as percepções de antigos e novos membros da equipe um mês após o início das atividades conjuntas. Para registro e transcrição das entrevistas, foi usado um gravador portátil por um pesquisador independente, para que os profissionais entrevistados se sentissem à vontade para expor suas percepções, uma vez que um dos autores faz parte da equipe. As entrevistas, com duração média de $30 \mathrm{~min}$, foram previamente autorizadas pelo gestor e realizadas em seu ambiente de trabalho apenas na segunda quinzena do mês de maio de 2020 e em horário agendado de acordo com a conveniência dos entrevistados.

Atendendo ao proposto por Bardin (2005), os três procedimentos metodológicos da análise de conteúdo foram seguidos rigorosamente. Na pré-análise, foram escolhidos os dados obtidos na análise documental realizada entre 1ํㅡㄹ de janeiro a 25 de junho de 2020 e na observação participante, realizada durante os meses de abril a maio de 2020, além de separar os trechos das entrevistas que fossem considerados representativos para atender ao objetivo deste estudo. $\mathrm{Na}$ fase de exploração do material, os dados das entrevistas, bem como da análise documental e da observação participante sofreram novo recorte, a fim de identificar a relação entre o aumento das relações interpessoais e a eficiência da assistência prestada. A fase de tratamento dos dados que consiste na 
interpretação dos dados de acordo com o quadro teórico e com o objetivo do trabalho é apresentada na seção a seguir.

Em virtude da pandemia do COVID-19, optou-se por não entrevistar indivíduos que compõem a população em situação de rua, evitando a possibilidade de contaminação, uma vez que os equipamentos de proteção individual utilizados na assistência dificultam a entrevista.

\section{Resultados}

$\mathrm{Na}$ observação participante, foi possível verificar uma forte resistência dos membros que já faziam parte do Consultório na Rua antes do ingresso dos novos colegas. Como todos os processos já existiam, o que envolvia a inclusão dos dados de atendimento no sistema informatizado que alimenta os dados da vigilância em saúde federal, a gestão municipal esperava que esses conhecimentos fossem compartilhados com os novos membros, o que não ocorreu de forma espontânea nas quatro semanas iniciais. Os profissionais médicos também se mostraram distantes, sendo incapazes de um diálogo cordial com os novos membros, assim como todos os demais membros da equipe.

Uma enfermeira da equipe antiga mostrou-se bastante contrariada ao ser informada que seu horário seria das 9 às 18h, declarando que por cinco anos ela trabalhara das 8 às 17h. Como demorou para entregar seus documentos para efetivar sua contratação pelo hospital filantrópico, a vaga das 8 às 17h já fora ocupada pela profissional contratada no recrutamento externo. A fim de estabelecer um bom relacionamento, a nova enfermeira aceitou fazer um rodízio de horário com a outra colega, alternando diariamente sua entrada e saída.

Entretanto, ficou evidenciado que, a despeito desse ato, os relacionamentos dentro da equipe continuaram com problemas. No dia em que a nova enfermeira ficaria responsável por encerrar as atividades às 18h, solicitou informações de como proceder, inclusive em relação às chaves para fechar a porta do setor. Como não obteve resposta, acabou sendo informada pela entrevistada T4 sobre o local da guarda das chaves, bem como os demais processos para encerramento das atividades. Além disso, durante toda a primeira semana, a equipe que saía às $17 \mathrm{~h}$ não se despedia dos demais colegas.

O gestor, um enfermeiro, também contratado pelo hospital filantrópico em regime de 4 horas diárias, não possuía experiência anterior em gestão e já trabalhava para outra organização em regime de plantão noturno. Questionado por T2 se não ficaria cansado em trabalhar em jornada dupla, explicou que seu trabalho era tranquilo e que, em geral, dormia a noite toda, o que provocou uma troca de olhares entre os membros da equipe. Mais tarde, T2 comentou com os demais membros que o novo gestor não parecia ter experiência assistencial ou em gestão.

Durante o tempo de observação, foram feitas reuniões de toda a equipe às sextasfeiras à tarde, escolhido por ser um turno com baixa procura dos serviços pela população em situação de rua. Nesses encontros, foi possível observar que o profissional T1 sentava-se de costas para os demais membros, dando atenção ao seu celular e sem que isso tivesse gerado qualquer observação do gestor. Também não havia a preocupação em fixar metas, estabelecer indicadores ou tratar, de forma reflexiva, sobre formas de melhorar os processos internos dada a diversidade das experiências dos membros da equipe e as peculiaridades do público-alvo. A escala com a divisão das tarefas e seus respectivos responsáveis também não foi elaborada.

Dada a inexperiência do profissional contratado como gestor, ele solicitava o acompanhamento da enfermeira que reclamou da mudança de horário e que era a gestora da antiga equipe. Consequentemente, os atendimentos realizados pela enfermeira restante eram prejudicados, já que diversos exames são feitos durante a 
consulta de enfermagem, podendo levar de 15 a $60 \mathrm{~min}$, dependendo das características do paciente. Além disso, a busca ativa não ocorria nesses turnos, pois não era possível deixar a Unidade sem uma enfermeira.

Como o setor funcionava de segunda à sexta-feira, das $8 \mathrm{~h}$ às $18 \mathrm{~h}$, havia uma equipe, conforme preconiza a Política Nacional de Atenção Básica que instituiu o Consultório na Rua, que permanecia na Unidade, enquanto a outra deslocava-se pelas ruas da cidade em uma van da prefeitura, ora atendendo a solicitações de assistência à população em situação de rua feitas pela comunidade, ora abordando diretamente essa população, a fim de estreitar os laços de confiança e atrair esses cidadãos para um atendimento completo na Unidade. Uma vez por semana, em lugar da van, a equipe utilizava um ônibus adaptado como base para a realização de consultas, exames e vacinação. O local para o atendimento dependia de acesso à fonte de energia para o funcionamento das instalações, o que reduzia as possibilidades de estacionamento.

Durante a análise documental, foi identificado que os dados das atividades realizadas não estavam atualizados no sistema informatizado desde a primeira quinzena de janeiro de 2020. Questionada, a entrevistada E1, então responsável por sua inserção, argumentou que, diante da possibilidade de demissão em função das sucessivas derrotas nas ações judiciais, não se sentia comprometida com suas atividades. Após acesso aos dados inseridos no sistema e aqueles não inseridos, foi possível evidenciar que, no período entre $1^{\circ}$ de janeiro a 21 de abril de 2020, foram realizados 1.035 atendimentos, enquanto entre 22 de abril a 25 de junho, o total de atendimentos foi de 3.649 .

Os profissionais entrevistados foram questionados como percebiam o trabalho com a equipe composta por profissionais novos e antigos.

A entrevistada $A 1$ foi escolhida para ser a primeira profissional por já estar naquela unidade há quase duas décadas e por ser aquela que a população em situação de rua tinha como referência assistencial, significando que seus vínculos com essa população estavam bastante sólidos:

\begin{abstract}
A1: (...) eu faço o meu trabalho do mesmo modo que sempre fiz, independente de quem viesse comigo. Reparei que a nova enfermeira se aproxima mais dos nossos pacientes do que as anteriores. Ela procura se sentar ou se abaixar para ficar na mesma altura que nossos pacientes, o que faz com que eles não se sintam inferiores a ela. Outra coisa que vi é que alguns já sabem o nome dela, o que não é comum em tão pouco tempo. (...) Percebi que eles não se falam. Ninguém passou nada. Uma das coisas mais importantes no atendimento na rua é saber o que pode ser dado para os nossos pacientes. Eu vi a novata dando duas máscaras para um e dois kits de higiene bucal para um outro. Não é que a gente não tenha para dar. É que a vivência na rua nos ensinou que se você der mais de um, eles ficam com um e vendem o outro para comprar pedra.
\end{abstract}

A entrevistada D1 declarou que não se sentia bem recebida pela equipe: “(...) viram a cara pra mim, mas eu não fiz nada. Mal cheguei!".

A entrevistada S1, também nova na equipe, relatou as dificuldades de se relacionar com os demais colegas, mas que já conseguira compreender a má recepção à entrevistada D1, com quem trabalha mais diretamente:

S1: (...) elas me disseram que o dentista anterior era muito querido por todos, mas como demorou a entregar os documentos, acabou perdendo a vaga para ela. Eles a detestam! Querem que ela desista, para que ele possa voltar.

\footnotetext{
A entrevistada P1 entende que é normal o estranhamento inicial entre novos e antigos membros:
}

P1: (...) não vejo razão para que não aconteça um distanciamento. Afinal, não se conhecem e os mais novos acabaram tirando o lugar de outros mais antigos que perderam os prazos de entrega dos documentos. Só o tempo, para que se 
conheçam melhor!

A entrevistada M1 declara que não percebe desarmonia entre novos e antigos:

M1: (...) Eu fico no meu consultório esperando que me enviem os pacientes. Não tenho tempo para ficar conversando com os outros. Quando não estou atendendo, estou me atualizando na internet.

Por outro lado, a entrevistada M2 que, assim como M1 pertencia à antiga equipe, tem percepção diferente:

M2: (...) eu vejo que se ajudam pouco. Uns técnicos trabalham mais e uma enfermeira que já era a minha colega passa a primeira hora fazendo outras coisas. Não sei se é trabalho, porque não é meu problema, mas vejo que ela evita atender os pacientes.

As entrevistadas T2, T3 e T4 apresentaram percepção semelhante em relação ao relacionamento dos membros novos e antigos:

T4: (...) sou a mais antiga de todas e com mais experiência na assistência. Eu fiquei meio sem jeito de não passar as coisas para os mais novos, mas já havíamos combinado que não íamos facilitar a vida deles. Elas ocuparam os lugares das nossas colegas. Mas logo no primeiro dia, acabei dizendo para a enfermeira novata como fazia para fechar a Unidade. As outras ficaram meio bravas comigo.

T3: (...) olha, tenho vergonha de admitir que eu fiz o possível para não ajudar a enfermeira nova, mas com o tempo eu vi que só ela trabalhava e atendia os pacientes, enquanto a outra vive indo pra reunião com o gestor. Tem dia que fico sem jeito de dar mais paciente pra ela. Outro dia pedi ajuda à médica para fazer o papel de enfermeira, ajudando nas consultas (a entrevistada M2 segundo ela). E ela foi ajudar sem reclamar. Não se se teria ido se fosse a outra enfermeira.

T2: (...) eu não aguentei mais o que a nossa antiga chefe tem feito. Ela ainda acha que é gestora e quase não atende os pacientes. Quando atende, nos casos mais difíceis, pede para passar no outro horário que ela sabe que será o da outra enfermeira. Não sei se é preguiça ou se ela não sabe fazer os testes.

Para o entrevistado $T 1$, as tarefas estão mal divididas, prejudicando os mais antigos: "(...) eu já reclamei na reunião que só eu coloco os dados de TB no sistema. Ninguém me ajuda!".

A entrevistada E1 também declara sentir-se prejudicada pela entrada dos novos colegas:

E1: (...) eu fui gestora 5 anos e tinha a minha vida organizada no horário das 8 às 17h. Não achei justo me tirarem do meu horário. Só não tá pior, porque a outra enfermeira aceitou ficar revezando comigo, mas não é a mesma coisa. É como se ela estivesse me fazendo um favor e eu não gosto disso. Não ensinei nada a ela, porque não ganho pra isso. Agora, andam fazendo a minha caveira para o gestor, porque ele me chama para ir nas reuniões externas. Eu não tenho culpa! E a novinha parece que gosta de atender; então eu faço parte dos relatórios que estão atrasados e deixo os atendimentos pra ela. Ela nunca reclamou pra mim e sei que não reclamou [para o] gestor.

Após a realização dessas entrevistas, a entrevistada T1 solicitou novo encontro com o pesquisador responsável pela coleta de dados desta etapa. Com ela, vieram as entrevistadas T4 e S1. T3 pediu para acrescentar à sua fala anterior:

T3: (...) lembra que eu te disse que tinha vergonha de não ajudar os novos colegas? Pois é, eu [estava] errada! Nos dias que a enfermeira nova entrava às 
8h, ela reparava que do lado de fora da Unidade, já tinha uma fila para atendimento. Ela conversou com alguns e descobriu que às $6 \mathrm{~h} 30 \mathrm{~min}$ eles têm de sair dos albergues e aí eles vêm direto pra cá. $E$ às 4 da tarde, eles têm de voltar para o albergue para disputar um lugar pra dormir. E a gente já tá aqui há 5 anos e nunca deu bola pra isso. Graças a ela, hoje atendemos das 7 às $17 \mathrm{~h}$ e não ficamos mais paradas depois das 5, porque ninguém aparecia para ser atendido. Claro, né? Estavam todos na fila do abrigo! E a outra enfermeira voltou a entrar às $8 h$, mas do jeito que ela é, vai reclamar porque não entra às $7 h$.

A entrevistada T4 complementou:

T4: (...) no começo, eu achava que o sorriso dela era para nos provocar. Quando você nos entrevistou, eu ainda não a conhecia bem. Mas quando eu vi que ela largava o almoço para atender, porque a outra enfermeira [estava] se amarrando, percebi que ela gostava do que fazia. E aí eu passei a respeitá-la e a ensinar a mexer no sistema. Muita coisa ela aprendeu sozinha, mas tem outras coisas que só os mais antigos dominam.

Para $\mathrm{S} 1$, os problemas iniciais de relacionamento com os mais antigos causaram problemas apenas no aprendizado do sistema informatizado, já que sua atividade é ligada à D1. Mas ela fez questão de corroborar as palavras das colegas, acrescentando:

\begin{abstract}
S1: Quando vi que podíamos fazer a diferença a essas pessoas em dificuldades, passei a pedir para ir nas saídas de van com a enfermeira nova. Eu fazia a minha consulta nos pacientes e recomendava melhorias na escovação ou uma ida na nossa Unidade para fazer um tratamento mais completo. Me faz muito bem saber que posso fazer a diferença na vida das pessoas. E muito legal! Além disso, tenho visto que os pacientes abordados com uma atenção diferenciada acabam indo à Unidade e levando seus colegas para receberem tratamento.
\end{abstract}

\title{
5. Discussão
}

A opção do hospital filantrópico em manter os antigos membros e adicionar novos profissionais à Unidade parece ter sido a razão para as dificuldades encontradas para a construção de um ambiente propício à realização das atividades assistenciais. As dificuldades podem ser evidenciadas tanto na insatisfação da enfermeira mais antiga pela troca de horário quanto nas declarações das entrevistadas mais antigas de que havia uma predisposição para não ajudar os mais novos. Isso acaba se refletindo no desconforto tanto daqueles que produzem os serviços quanto na qualidade de quem os recebe (XING et al., 2013). É notável, também, a diferença no quantitativo de atendimentos realizados nos 112 dias anteriores à parceria com o hospital filantrópico (1.035), correspondendo a $28,36 \%$ do volume total de atendimentos (3.649) realizados em apenas 65 dias, após o início da referida parceria. Tanto a insatisfação dos antigos membros da equipe quanto a expressiva elevação dos números de atendimento sugerem que que os profissionais mais antigos não eram capazes de observar a importância de seu trabalho, o que acabou se refletindo no seu sentimento de pertencimento (GALLETTA et al., 2016).

A aparente ausência do gestor, seja pela não estabelecimento de metas e indicadores, seja pela não realização de escalas com a distribuição das atividades, ou ainda pela falta de firmeza em não solicitar ao funcionário T1 que deixasse de ficar de costas durante as reuniões dando atenção apenas ao celular, sugerem uma falta de preparo para a função. Deveria ser parte de suas preocupações como gestor a criação de estratégias de negociação capazes de gerar melhorias na comunicação e na construção da confiança entre os membros da sua equipe, o que poderia ter facilitado o compartilhamento dos conhecimentos entre profissionais novos e antigos (PARNABY; TOWILL, 2008; CLIFF, 2012). Essas falhas na capacidade de liderança parecem se refletir, portanto, na qualidade dos relacionamentos entre os diversos profissionais, o que 
acaba impactando a tão desejada promoção do acolhimento e de uma escuta cultural qualificada para a população em situação de rua (VASCONCELOS; PARREIRA, 2017).

As dificuldades criadas pelos funcionários mais antigos na inserção dos mais novos nas atividades assistenciais são evidenciadas nas entrevistas, notadamente dos entrevistados P1, M1, T2, T3 e T4. Como pertenciam à antiga organização e sua gestora era a atual enfermeira, cuja maior preocupação parecia ser o horário de entrada, demonstraram não se sentir parte do processo de assistência, o que possivelmente levou à redução na sua satisfação com 0 trabalho e no espírito de cooperação e comprometimento (GALLETTA et al., 2016; YOON; KIM; SHIN, 2016).

Com o passar do tempo, a percepção de que a nova enfermeira era realmente comprometida com o trabalho contribuiu para a construção das relações interpessoais (GALLETTA et al., 2016), o que pode ser percebido na entrevista de T3 ao declarar que pediu para a médica (M2) ajudar a enfermeira nova diante do volume de pacientes e da ausência da enfermeira mais antiga. T3 acrescentou que não sabia se M2 teria a mesma disposição se a enfermeira fosse a mais antiga. O comprometimento com o trabalho como reflexo da construção das relações interpessoais também pode ser evidenciado pelas declarações da entrevistada $\mathrm{S} 1$ que passou a pedir para compor a equipe que realiza a busca ativa, pois se sentia bem consigo mesma ao fazer a diferença para o bem-estar das pessoas. O resultado é o ganho em eficiência na assistência prestada por meio do acolhimento e da escuta qualificada (VASCONCELOS; PARREIRA, 2017).

Em relação ao atendimento à população em situação de rua, a entrevistada $A 1$ confirma a importância do estabelecimento das relações interpessoais também entre a assistência e os pacientes, ao comentar a atitude da enfermeira nova de se colocar no mesmo nível que eles ao se abaixar ou se sentar. Essa atitude acaba por gerar comprometimento nos demais membros da equipe ao ver sua colega adotar uma escuta cultural qualificada, possibilitando conhecer as demandas e necessidades desta população (VASCONCELOS; PARREIRA, 2017).

Esse dado também pode ser evidenciado na declaração de T3 de que foi necessário a enfermeira nova conversar com as pessoas na fila da Unidade, para que o horário vigente há 5 anos fosse antecipado para melhor atender a essa população. Isso significa, também, que a equipe, ao abraçar a ideia, praticou a empatia, pois foi capaz de se colocar no lugar do outro (DUARTE, 2018), o que só é possível se os profissionais da saúde se sentirem comprometidos com o trabalho que realizam (YOON et al., 2016). $\mathrm{O}$ comprometimento com o serviço prestado acabou se refletindo, ainda, no comparecimento voluntário dos pacientes atendidos na rua que se faziam acompanhar de amigos que não conheciam ou usavam o serviço, conforme atesta a entrevistada S1.

\section{Conclusão}

Ao assumir os serviços prestados pelo Consultório na Rua, o hospital filantrópico decidiu por absorver os funcionários já existentes. Por seu turno, diante da possibilidade de desemprego iminente com a troca de organização responsável pelo fornecimento dos recursos humanos para aquela Unidade, esses funcionários deixaram de fazer parte de suas atividades, como o preenchimento de relatórios, o que sugere a redução de sua satisfação.

A relação interpessoal da equipe antiga parecia estar consolidada, uma vez que seus membros não só haviam combinado de não compartilhar os conhecimentos com os novos integrantes, como também faziam o possível para gerar desconforto àqueles que haviam ocupado o lugar de colegas por quem tinham estima. Entretanto, não foi isso que foi evidenciado durante a coleta de dados. À medida que os novos profissionais mostravam genuína preocupação com o atendimento à população em situação de rua, mais as falhas no relacionamento da antiga equipe apareciam. O respeito pela antiga 
gestora parece ter-se transformado em aversão diante das críticas à sua ausência no atendimento por comparecer às reuniões externas com o gestor. Além disso, a preocupação com o maior volume de atendimentos pela enfermeira nova, sem que ela tivesse feito qualquer comentário ou reclamação a respeito, indica que os demais membros passaram a aceitá-la como parte do grupo.

Como é uma equipe pequena que deve se dividir em atendimento presencial e na rua, as constantes ausências provocam uma redução nos atendimentos feitos e na captação ativa de novos cidadãos àquela que é a sua principal porta de acesso aos serviços de saúde. Contribui para essa aversão a percepção por parte da equipe antiga da falta de capacidade do enfermeiro escolhido como gestor. Como tem apenas 4 horas por dia para prestar seu serviço, gasta boa parte desse tempo em reuniões externas, 0 que não parece não permitir que conheça ou proponha mudanças nos processos internos.

Por sua vez, a ampliação de membros da equipe empenhados em construir um relacionamento com a população em situação de rua, consolidando aquilo que vinha sendo construído pela entrevistada A1 de forma solitária, evidencia que parte dos demais membros passou a sentir-se satisfeita com o trabalho que fazem, tornando-se comprometidos em oferecer uma assistência qualificada.

Diante dos dados apresentados, pode-se evidenciar a importância da construção das relações interpessoais não só entre os membros da equipe, mas também entre esta e a população em situação de rua. Os ganhos foram simultâneos para os dois lados. Enquanto a população passa não só a ter uma assistência qualificada, sentindo-se integrados à sociedade, a equipe assistencial percebe um aumento em sua satisfação na realização das atividades assistenciais, diante do bem-estar que geram naquelas pessoas. A construção de vínculos e a promoção da confiança entre a equipe assistencial e a população de rua só parecem ter sido viabilizadas quando as relações interpessoais da equipe começaram a consolidar-se. Por outro lado, ganha visibilidade a importância na escolha de um líder que seja capaz de interagir com aqueles que não se comprometem na mesma intensidade dos demais, utilizando técnicas de gestão apropriadas para cooptá-los nesse esforço coletivo, ou ainda, quando for o caso, de solicitar o seu afastamento definitivo.

Como limitações deste trabalho estão o tempo de observação e a análise apenas do primeiro trimestre de funcionamento. Seria interessante realizar um estudo longitudinal para verificar como agiriam os membros ora comprometidos no caso de uma rotatividade natural de parte dos funcionários. Um novo estudo permitiria verificar se o tratamento pouco amistoso que os novos profissionais receberam se repetiria ou se a inserção de novos membros seria feita de forma a não gerar perdas na qualidade dos serviços prestados.

\section{Referências}

BARDIN, L. Análise de conteúdo. Lisboa: Edições 70, 2005.

BÖHME, T.; WILLIAMS, S.; CHILDERHOUSE, P.; DEAKINS, E.; TOWILL, D. Squaring the circle of healthcare supplies. Journal of Health Organization and Management, $v$. 28, n. 2, p. 247-265, 2014.

CLIFF, B. Patient-centered care: the role of healthcare leadership. Journal of Healthcare Management, v. 57, n. 6, p. 381-383, 2012. 
BRASIL. Ministério da Saúde. Material de trabalho para a II Oficina Nacional de Consultórios de Rua do SUS. Coordenação Nacional de Saúde Mental. Brasília: Ministério da Saúde, 2010.

DA SILVA, V. et al. The practice of comprehensive care management: experience report. Journal of Nursing UEPE On Line, v. 11, n. 2, p. 792-797, 2017.

DUARTE, A. H. C. O Sistema Único de Saúde e seus alcances: reflexões acerca do processo de trabalho do consultório na rua. 2018. 100f. Dissertação (Mestrado em Serviço Social) - Programa de Pós-Graduação em Serviço Social, Pontifícia Universidade Católica do Rio Grade do Sul, Porto Alegre, RS, 2018.

FRYER, A. K.; TUCKER, A.L.; SINGER, S. J. The impact of middle manager affective commitment on perceived improvement program implementation success. Health Care Management Review, v. 43, n. 3, p. 218-228, 2018.

GALLETTA, M. et al. Nurses well-being in intensive care units: study of factors promoting team commitment. Nursing in Critical Care, v. 21, n. 3, p. 146-156, 2016.

GLOBO. Porto Alegre tem mais de 2,6 mil moradores em situação de rua. Prefeitura de Porto Alegre. Jul. 2020. Disponível em: <https://g1.globo.com/rs/rio-grande-dosul/noticia/2020/07/14/porto-alegre-tem-mais-de-26-mil-moradores-em-situacao-de-ruadiz-fasc-ong-alerta-para-aumento-no-numero-durante-pandemia.ghtml> Acesso em: 02 set. 2020.

JORNAL DO COMÉRCIO. Prefeitura de Porto Alegre oferece vacina da gripe à população em situação de rua. Prefeitura de Porto Alegre. Jun. 2020. Disponível em: <https://www.jornaldocomercio.com/_conteudo/geral/2020/06/742866-prefeitura-oferecevacina-da-gripe-a-populacao-em-situacao-de-rua.html>. Acesso em: 02 set. 2020.

KLEIN, A. Z.; SILVA, L. V. da; MACHADO, L. Metodologia de Pesquisa em Administração: uma abordagem prática. São Paulo: Atlas, 2015.

LE, B. M. et al. O. Communal motivation and well-being in interpersonal relationships: An integrative review and meta-analysis. Psychological Bulletin, v. 144, n. 1, p. 1-25, 2018.

PARNABY, J.; TOWILL, D. R. Enabling innovation in health-care delivery. Health Services Management Research, v. 21, n. 3, p. 141-154, 2008.

PREFEITURA DE PORTO ALEGRE. Prefeitura firma acordo com instituições para atenção primária. Prefeitura de Porto Alegre. Dez. 2019a. Disponível em: $<$ https://prefeitura.poa.br/gp/noticias/prefeitura-firma-acordo-com-instituicoes-paraatencao-primaria> Acesso em 02 set. 2020.

PREFEITURA DE PORTO ALEGRE. Consultório de Rua. Prefeitura de Porto Alegre. Nov. 2019b. Disponível em: <https://prefeitura.poa.br/gp/noticias/prefeitura-firma-acordocom-instituicoes-para-atencao-primaria >. Acesso em: 02 set. 2020.

SILVA, T. D.; NATALINO, M.; PINHEIRO, M. B. População em situação de rua em tempos de pandemia: um levantamento de medidas municipais emergenciais. Nota Técnica $\mathbf{n}^{\circ}$ 74. Brasília: Diretoria de Estudos e Políticas do Estado, das Instituições e da Democracia; Instituto de Pesquisa Econômica Aplicada (IPEA), 2020. 
TEIXEIRA, M.; ENGSTROM, E.; TAVARES, R. Consultório na rua: análise da prática das equipes de consultório na rua do Rio de Janeiro. Rio de Janeiro: FIOCRUZ/ENSP; 2019.

TUCKER, A. L. An Empirical Study of System Improvement by Frontline Employees in Hospital Units. Manufacturing \& Service Operations Management, v. 9, n. 4, p. 492505, 2007.

VASCONCELOS, J. P. R.; PARREIRA, C. M. S. F. Inovação na Atenção Básica à Saúde: o trabalho do cotidiano na estratégia saúde da família em Ceilândia (DF). Revista Eletrônica Gestão \& Saúde, Brasília, v. 8, n. 02, p. 270-283, 2017.

XING, Y. et al. Operations research (OR) in service industries: a comprehensive review. Systems Research and Behavioral Science, v. 30, n. 3, p. 300-353, 2013.

YEE, R. W. Y.; GUO, Y.; YEUNG, A. C. L. Being close or being happy? The relative impact of work relationship and job satisfaction on service quality. International Journal of Production Economics, v. 169, n. C, p. 391-400, 2015.

YOON, J.; KIM, M.; SHIN, J. Confidence in delegation and leadership of registered nurses in long-term-care hospitals. Journal of Nursing Management, v. 24, n. 5, p. 676-685, 2016. 